\title{
Comparison of Adrenergic Beta-blocking Drugs in Angina Pectoris
}

\author{
B. SHARMA, \\ M. K. MEERAN, \\ M. C. GALVIN, \\ A. T. TULPULE, W. WHITAKER, \\ S. H. TAYLOR
}

British Medical fournal, 1971, 3, 152-155

\section{Summary}

The symptomatic, electrocardiographic, and haemodynamic effects of two adrenergic beta-blocking drugs, oxprenolol and propranolol, have been compared in equipotent intravenous doses in six patients with uncomplicated angina pectoris during treadmill exercise. The method of comparison included double-blind assessment and analysis with placebo control and randomized serial comparison in each patient. Both drugs produced an equal amelioration in symptoms in most of the patients. This was closely correlated with improvement in the electrocardiographic changes and a significant reduction in the exercising heart rate and systemic arterial pressure. This method of double-blind combined subjective and objective assessment carries distinct advantages in the comparative assessment of drug treatments in angina pectoris.

\section{Introduction}

Though a number of adrenergic beta-blocking drugs are available for the symptomatic treatment of severe angina pectoris there is little information on their comparative effectiveness. This report concerns a comparative study of the symptomatic, electrocardiographic, and circulatory effects of two such drugs, oxprenolol and propranolol, in patients with angina pectoris.

\section{Patients and Methods}

Six men aged 39 to 58 (mean 47) years with uncomplicated angina pectoris were studied. Their average weight was $72 \cdot 6$ (range 58-89) kg. None were obese, hypertensive, or diabetic, none had hyperlipidaemia, and none had had a previous myocardial infarction or history of other heart disease. In all cases the angina was induced solely and repeatedly by exercise; the length of angina history ranged from eight months to five years. No patient had received previous treatment other than glyceryl trinitrate.

The resting electrocardiogram was normal in all patients; during treadmill exercise the $S-T$ segment in the standard and chest leads V 4-6 was depressed by more than $0.05 \mathrm{mV}(1 \mathrm{~mm})$ in all cases during anginal pain. The chest radiograph was normal and the cardiothoracic ratio was less than $50 \%$ in all patients. All had normal left ventricular function at rest but evidence of severe reversible impairment of left ventricular performance during exercise as previously described (Sharma and Taylor, 1970).

Cardiovascular Unit, University Department of Medicine, the General Infirmary, Leeds LS1 3EX

B. SHARMA, D.C.H., M.R.c.P.ED., Senior Ciba Research Fellow and Honorary Lecturer in Medicine

M. K. MEERAN, M.R.C.P., F.C.P.(S.A.), Registra

M. C. GALVIN, M.B., CH.B., Imperial Chemical Industries Research Fellow

The purpose, investigative programme, and possible clinical benefits of the study were discussed with each patient; without inducement all consented willingly to the series of studies.

\section{DESIGN OF INVESTIGATION}

The speed and slope of the treadmill was adjusted so that in each patient anginal pain did not occur before the third minute of exercise and all were able to complete six minutes of continuous exercise; a reproducible end-point was thus achieved. The patient was also trained to indicate the onset and severity of his pain by a finger-operated light-switch. Pain was arbitrarily graded as mild, moderate, or severe; "mild" pain was defined as early discomfort or tightness of the chest, "moderate" as a feeling of severe constriction but not severe enough to prevent walking, and "severe" was categorized as of that severity which urgently required the patient to stop exercise. Precautions were taken to control factors which might have induced erroneous changes in exercise tolerance. The laboratory temperature was controlled, apprehension among patients was reduced by familiarization with the technique, the studies were carried out at the same time each day and not earlier than one hour after a light carbohydrate meal, and only if the patient had not had an attack of angina during the previous four hours. After the reproducibility of each patient's symptoms had been established, the definite studies were carried out at the same time on alternate days.

Each study consisted of equal six-minute contiguous periods of sitting, standing, walking, standing, and sitting. Studies were carried out without injection, after intravenous saline injection $(10 \mathrm{ml})$, oxprenolol $(0.2 \mathrm{mg} / \mathrm{kg}$ body weight), or propranolol $(0 \cdot 2 \mathrm{mg} / \mathrm{kg})$. These doses of oxprenolol and propranolol have been shown to result in equal and complete blockade of the heart rate response to infusion of $20 \mu \mathrm{g}$ of isoprenaline per minute and to produce the maximum effect on the heart rate response to supine leg exercise, Valsalva manoeuvre, and ingestion of glyceryl trinitrate (Taylor et al., 1970; Majid et al., 1971). The placebo, oxprenolol, and propranolol studies were all started 10 minutes after the intravenous injection. The order was randomized and the content of the injection was unknown to the doctor and patient. Electrocardiographic and systemic arterial pressure records were recorded continuously throughout each study so that the exact time of the S-T depression could be determined. The records were analysed by observers who had no knowledge of the drug given. The study was, therefore, double-blind in design and analysis, placebo-controlled, randomized in order, and each patient served serially as his own control.

\section{TECHNIQUES, MEASUREMENTS, AND STATISTICAL METHODS}

Electrocardiographic chest lead V5 was recorded from an adhesive-disc electrode. The linear S-T segment depression from the isoelectric line was measured immediately after the $S-T$ junction and averaged over five complexes during each minute of study, as previously described (Taylor and Sharma, 1971). Measurements were averaged throughout each period of rest and for the final two minutes of exercise during treadmill walking. Systemic arterial pressure was measured in the aorta 
from a nylon catheter $(55$ by $0.1 \mathrm{~cm}$ ) introduced percutaneously into a brachial artery. The E.C.G. and systemic arterial pressure were recorded continuously at 5 and $125 \mathrm{~mm} / \mathrm{sec}$ alternately on an ultraviolet recorder with $32-\mathrm{cm}$ focal length galvanometers. Mean systolic and diastolic pressures were measured by planimetry from the aortic pressure pulse (Taylor et. al., 1967). Electrocardiographic, heart rate, and systemic arterial pressure measurements were averaged over the final four minutes of each six-minute period except during walking, when the measurements were averaged over the final two minutes of exercise. Probability of significance of differences was calculated from comparison of test and control paired values in the same individual (Fisher, 1946).

\section{Results}

\section{SYMPTOMS}

No patient had pain during sitting or standing in any of the four studies. In the control study all six patients developed mild pain during treadmill walking (Fig. 1), which progressed to moderate intensity in all and to severe pain in four. After saline injection and at the same level of exertion all the patients developed both mild and moderate pain which progressed to severe in three. After both intravenous oxprenolol and propranolol pain was abolished in two patients who had previously developed severe pain at the same level of exertion. The remaining four still developed mild pain which progressed to moderate in three and to severe in one after each drug.

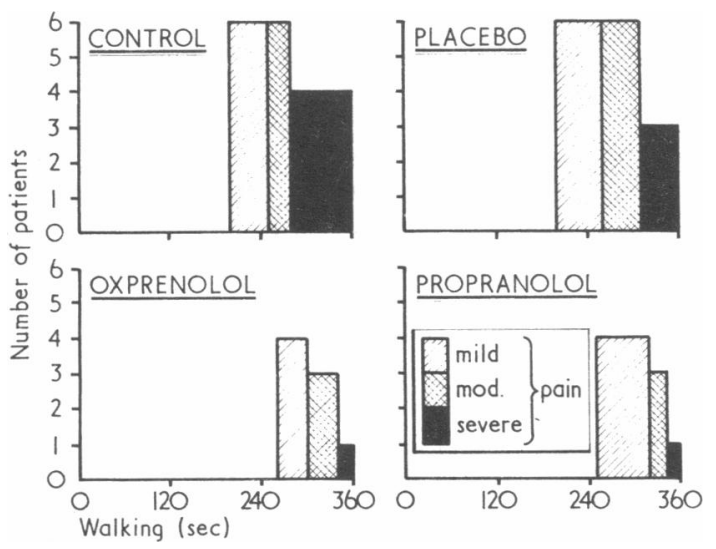

FIG. 1-Comparison of effects of oxprenolol and propranolol on time of onset and intensity of pain during exercise in patients with angina pectoris.

Effect of Oxprenolol and Propranolol on Symptoms and Averaged Electrocardiographic and Haemodynamic Measurements during Exercise-induced Angina Pectoris

\begin{tabular}{|c|c|c|c|c|c|c|c|}
\hline \multirow[b]{2}{*}{ Study } & \multicolumn{3}{|c|}{ Time Course of Pain (sec) } & \multirow{2}{*}{ 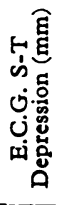 } & \multirow{2}{*}{ 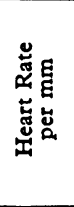 } & \multirow{2}{*}{ 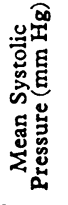 } & \multirow{2}{*}{ 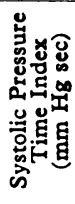 } \\
\hline & 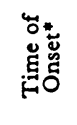 & 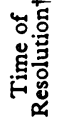 & 预总 & & & & \\
\hline $\begin{array}{l}\text { Control } \\
\text { Placebo } \\
\text { Oxprenoloi } \\
\text { Propranolol }\end{array}$ & $\begin{array}{l}203 \\
200 \\
261^{*} \\
251 \dagger\end{array}$ & $\begin{array}{l}180 \\
150 \\
66+ \\
69\end{array}$ & $\begin{array}{l}337 \\
310 \\
165^{*} \\
178^{*}\end{array}$ & $\begin{array}{l}2.5 \\
2.4 \\
1.0 \$ \\
1.2 \dagger\end{array}$ & $\begin{array}{l}134 \\
132 \\
104 \ddagger \\
103 \$\end{array}$ & $\begin{array}{l}127 \\
124 \\
113 \ddagger \\
110 \ddagger\end{array}$ & $\begin{array}{l}30 \\
31 \\
33 \\
32\end{array}$ \\
\hline
\end{tabular}

Significantly different from control measurements: $* P<0.05 .+P<0.02 . \$ P<0.01$. $\$ \mathrm{P}<0.001$.

After start of exercise.

The changes in time course of the pain were significantly modified by both drugs (see Table); there was no significant difference between the two drugs with respect to the delay in time of onset, the hastened time of recovery, or the total duration of pain.

\section{ELECTROCARDIOGRAPHIC CHANGES}

There was no significant $S-T$ depression during the initial sitting or standing periods in any patient in any of the four studies. During the final two minutes of exercise in the control study, when all patients had anginal pain, the average S-T depression was significantly greater than at rest $(2.5 \mathrm{~mm}$; $\mathbf{P}>0.01$ ) (Fig, 2, Table). After saline injection the time course and extent of the S-T segment depression $(2.4 \mathrm{~mm})$ was not significantly different from the changes during the control study. After both intravenous oxprenolol and propranolol the time of onset of the $S-T$ depression, its maximum extent at the same level of exertion as in the control study, and its time of resolution after exercise were all significantly reduced at the $2 \%$ level of confidence or greater; there was no statistically significant difference between the effects of the two drugs.

There were no other significant electrocardiographic changes; the average peak height of the $T$ wave during exercise was not significantly changed by either oxprenolol or propranolol.

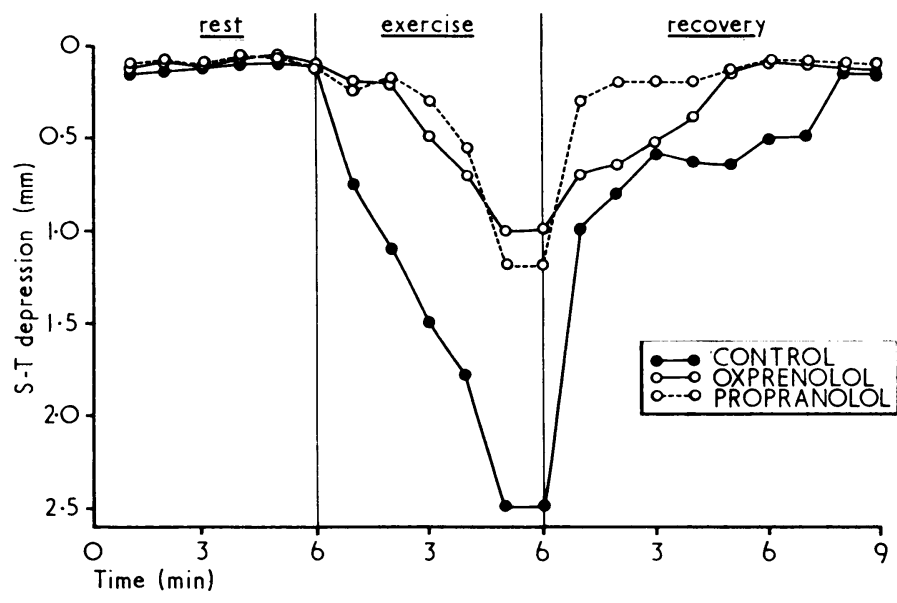

FIG. 2-Serial studies of effects of beta-blockage with oxprenolol and propranolol on the electrocardiogram during treadmill walking in patients with angina pectoris. Values are averaged; results following placebo were not significantly different from those of the control study at any time and are omitted for the sake of clarity.

\section{PAIN AND E.C.G. CHANGES AFTER BETA-BLOCKADE}

The electrocardiographic S-T segment changes correlated closely with the improvement in symptoms. In two patients in whom the symptoms were abolished by oxprenolol and propranolol the S-T segment depression was reduced from $3 \cdot 2$ and $2.9 \mathrm{~mm}$ respectively in the control study to 1.9 and 1.3 respectively after propranolol. In the single patient who had no relief from drugs the $S-T$ segment depression was $2.5,2.5$, and $2.9 \mathrm{~mm}$ in the control, oxprenolol, and propranolol studies respectively. The three remaining patients who experienced partial relief of symptoms after the two beta-blocking drugs all showed a reduction in $S-T$ segment depression of $1.5 \mathrm{~mm}$ or greater compared with the measurement in the control or placebo study.

\section{HEART RATE, SYSTOLIC, AND DIASTOLIC PRESSURES}

In the control study the average standing heart rate was 85/ $\mathrm{min}$; this increased to an average of $134 / \mathrm{min}$ during the final two minutes of exercise (Fig. 3 Table). The corresponding values in the placebo study were not significantly different 

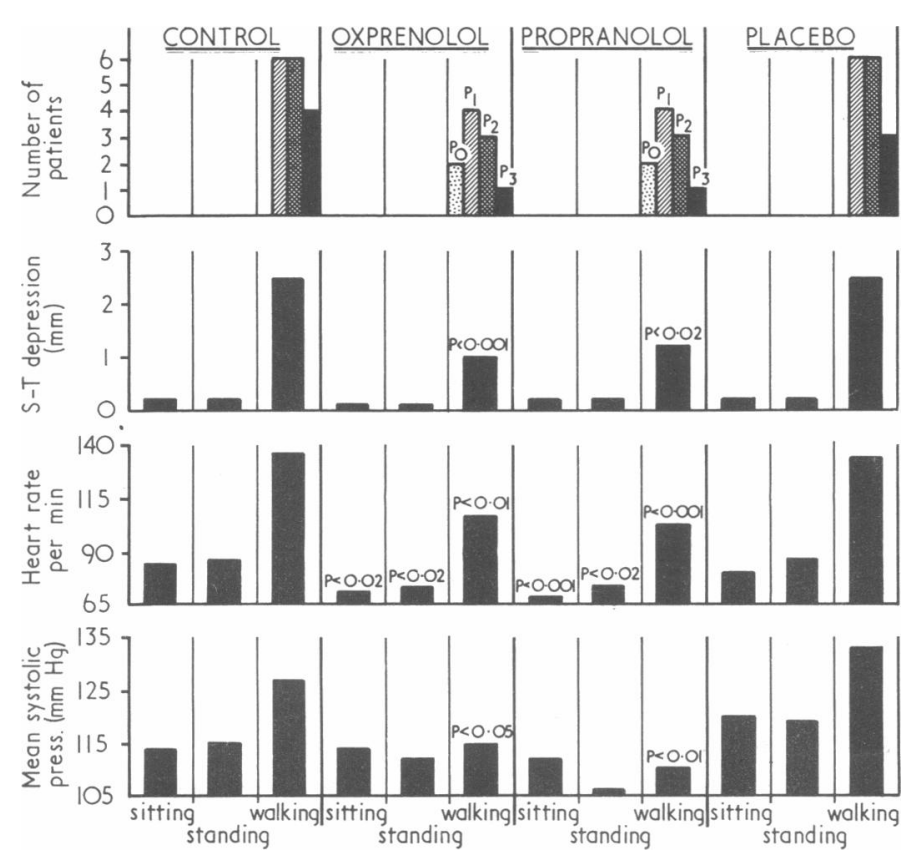

FIG. 3-Serial studies of correlated changes in pain, electrocardiographic S-T depression, heart rate, and systemic arterial pressure following betablockade with oxprenolol and propranolol. Values are averaged and the order of illustration is for graphic convenience only; the order of drug and placebo administration was randomized in each patient. $\mathbf{P}_{0}=$ No pain. $\mathbf{P}_{1}=$ mild pain. $\mathbf{P}_{2}=$ Moderate pain. $\mathbf{P}_{3}=$ Severe pain

from those in the control study. After oxprenolol the average standing heart rate at rest was $78 / \mathrm{min}(\mathrm{P}<0.02)$ and during exercise $104 / \mathrm{min}(P<0.01)$. After propranolol the average standing and walking heart rates were $76 / \mathrm{min}(P<0.02)$ and $103 / \mathrm{min} \quad(P<0.001)$ respectively. There was no significant differences between the effects of the two drugs on the standing and walking heart rates.

In the control study the average mean systolic and diastolic pressures during standing were 114 and $87 \mathrm{~mm} \mathrm{Hg}$ respectively, and during the final two minutes of treadmill exercise 127 and $94 \mathrm{~mm} \mathrm{Hg}$ respectively. There was no statistically significant difference between these values in the control and placebo studies. After oxprenolol there was no significant change in the average standing pressures but there was a significant reduction in the average mean systolic pressure during exercise to 113 $\mathrm{mm} \mathrm{Hg} \quad(P<0.01)$ and a significant reduction in the mean diastolic pressure to $79 \mathrm{~mm} \mathrm{Hg}(\mathrm{P}<0.02)$. After propranolol there was no significant change in the standing pressures but the mean systolic pressure during walking was significantly reduced to $110 \mathrm{~mm} \mathrm{Hg}(\mathrm{P}<0.01)$ and the mean diastolic pressure to $77 \mathrm{~mm} \mathrm{Hg}(\mathbf{P}<0.01)$.

The average left ventricular systolic pressure-time product during walking was unchanged after placebo, oxprenolol, or propranolol.

\section{Discussion}

The findings in this study showed that both beta-blocking drugs significantly delayed the onset, duration, and intensity of the exercise-induced pain in five of the six patients. This improvement in symptoms was accompanied by significant improvement in the electrocardiogram and closely correlated with simultaneous reductions in the heart rate and mean systolic pressure; there was no significant change in the systolic pressure-time product during angina after either drug. There were no significant differences between the subjective or objective effects of the two beta-blocking drugs. These results are given added validity by the fact that each patient was trained to an extent where the symptoms were reliably reproduced, every attempt was made to maintain identical conditions during each study, they were double-blind in both design and analysis, placebo controlled, randomized in order, and serially compared in each patient.

This study was not designed to give information on the relative effectiveness of beta-blocking drugs in angina; the small number of patients studied absolutely precludes any reliable inferences to be made on this point. Neither was it designed to distinguish those patients who could be expected to benefit from beta-blocking therapy.

Most studies showing improvement in anginal symptoms afforded by beta-blocking drugs have been open, single-blind, or double-blind assessments of symptomatic improvement. Few have been concerned with the correlated objective electrocardiographic and haemodynamic measurements and none seem to have been concerned to establish the degree of beta-blockade in the patients under study. Stern and Eisenberg (1969) showed that intravenous propanolol $(10 \mathrm{mg}$ ) had no effect on the S-T segment of resting normal subjects. Furberg (1967) and Biörck et al. (1968) stated that the S-T segment was unchanged during exercise but that there was a more rapid resolution of the changes after stopping work. However, both of these studies may be criticized from a dose-response aspect. The patients in the study of Furberg were restudied one hour after an oral dose of $5-20 \mathrm{mg}$; the reduction in heart rate or degree of betablockade after this small dose of drug was not stated. Biörck et al. used only $5 \mathrm{mg}$ of propranolol intravenously (about 0.07 $\mathrm{mg} / \mathrm{kg}$ ), a dose that produces only a relatively small degree of beta-blockade (Majid et al., 1971.

Gianelly et al. (1960), in directly relevant studies on 11 men in whom anginal pain was accompanied by typical S-T changes during treadmill exercise, showed a significant reduction in the $\mathrm{S}-\mathrm{T}$ segment depression after intravenous propranolol $(0 \cdot 15$ $\mathrm{mg} / \mathrm{kg}$ ). Prichard et al. (1970) reported similar electrocardiographic findings during bicycle exercise in angina patients after both propanolol and oxprenolol. As S-T segment depression is a relatively reliable objective clinical index of myocardial ischaemia in angina pectoris, the correlation of symptomatic and electrocardiographic changes is a potentially valuable objective measure of the efficacy of this type of antianginal treatment.

The improvement in symptoms in these patients is probably predominantly related to the decreased heart rate and reduced systemic arterial pressure. These two factors correlate closely and directly with myocardial oxygen consumption (Evans, 1917; Cohn and Steele, 1935; Sarnoff et al., 1958) and the onset of pain in angina patients (Robinson, 1967; Sharma et al., 1971). Withdrawal of sympathetic drive to the ventricles also reduces the speed of ventricular contraction, which may further reduce myocardial oxygen consumption (Sonnenblick et al., 1965a). Though it has been shown that the left ventricular volume and end-diastolic pressure are increased both at rest and during exercise in the non-ischaemic heart after beta-blockade (Sonnenblick et al., 1965b; Chamberlain, 1966; Gander et al., 1966; Majid et al., 1970), left ventricular filling pressure is often not increased during exercise in anginal patients after betablockade (Dwyer et al., 1968; Astrom, 1968; Sharma et al., 1970), probably due to the sparing effect of the reduced rate, pressure, and speed of contraction on the left ventricular myocardial oxygen consumption. By reducing myocardial oxygen demand and coronary blood flow requirements these factors outweigh any direct increase in coronary vascular resistance due to beta-blockade (Folle and Aviado, 1965; Klocke et al., 1965; McKenna et al., 1966; Whitsitt and Lucchesi, 1967).

The inherent difficulty of testing drugs in angina is shown by the large number of double-blind trials so far reported with beta-blocking drugs. Double-blind trials in this condition may be misleading for several reasons: angina is a symptomcomplex of varied aetiology and it is difficult to find a suitably large group of subjects with clinically stable and reproducible symptoms; in many patients the symptoms in everyday life are 
conditioned by non-random events; the condition is influenced by emotional and environmental factors; there is a high placebo response; and the common yardstick of the number of tablets of glyceryl trinitrate consumed is open to many undefined individual errors. For these reasons the methods used in these studies, which were designed to correlate symptoms with electrocardiographic and relevant haemodynamic measurements, form a useful investigative model for the assessment and comparison of effectiveness of treatment in exerciseinduced angina pectoris both in the individual patient and in field studies.

We wish to thank the many physicians and surgeons who referred patients to us; Sisters F. Ellis and R. Cox and the nursing staff of the medical professorial unit, the General Infirmary, Leeds, for their help and co-operation; Mr. R. Stafford and the technicians of the cardiovascular unit without whose valuable help this work would not have been possible; the catheter room nurses who afforded such essential help; Dr. H. W. Peers, of the department of statistics, University of Leeds, for advice and help with the statistical design of the study and analysis of the results; Sir Ronald Tunbridge and Professor R. J. Linden for their help and encouragement throughout. B.S. is a Senior Ciba Research Fellow, M.C.G. is an Imperial Chemical Industries Research Fellow. tion.

This work was assisted by a grant from the Wellcome Founda-

Requests for reprints should be addressed to Dr. S. H. Taylor, Department of Medicine, the General Infirmary, Leeds LS1 3EX.

\section{References}

Astrom, H. (1968). British Heart fournal, 30, 44.

Biörck, G., Eliasch, H., Pernow, B., and Rosén, A. (1968). Acta Medica Scandinavica, 184, 275.

Chamberlain, D. A. (1966). American fournal of Cardiology, 18, 321.

Cohn, A. E., and Steele, J. M. (1935). American fournal of Physiology,

Dwyer, E. M., jun., Wiener, L., and Cox, J. W. (1968). Circulation, 38,

Evans, C. L. (1917). Fournal of Physiology, 51, 91. Fisher, R. A. (1946). Stastistical Methods for Research Workers. Edinburgh,
Oliver and Boyd.

Folle, L. E., and Aviado, D. M. (1965). Fournal of Pharmacology and Experimental Therapy, 149, 79.

Furberg, C. (1967). Acta Medica Scandinavica, 181, 21.

Gander, M., Veragut, U., Kohler, R., and Luhty, E. (1966). Cardiologia, $49,17$.

Gianelly, R. E., Treister, B. L., and Harrison, D. C. (1969). American fournal of Cardiology, 24, 161 .

Klocke, F. J., Kaiser, G. A., Ross, J., jun., and Braunwald, E. (1965). Circulation Research, 16, 376.

McKenna, D. H., et al. (1966). Circulation Research, 19, 520

Majid, P. A., Benaim, M., and Taylor, S. H. (1971). British fournal of Pharmacology, In press.

Majid, P. A., Sharma, B., Saxton, C., Stoker, J. B., and Taylor, S. H. (1970). Postgraduate Medical fournal, November Supplement, p. 67.

Prichard, B. N. C., Aellig, W. H., and Richardson, G. A. (1970). Postgraduate Medical fournal, November Supplement, p. 77.

Robinson, B. F. (1967). Circulation, 35, 1075.

Sarnoff, S. J., et al. (1958). American fournal of Physiology, 192, 148.

Sharma, B., Majid, P. A., Galvin, M. C., and Taylor, S. H. (1970). Postgraduate Medical fournal, November Supplement, p. 72.

Sharma, B., Majid, P. A., Meeran, M. K., and Taylor, S. H. (1971). British Heart fournal. In press.

Sharma, B., and Taylor, S. H. (1970). Lancet, 2, 902.

Sonnenblick, E. H., Braunwald, E., Williams, J. F., and Glick, G. (1965a). fournal of Clinical Investigation, 44, 2051.

Sonnenblick, E. H., Ross, J., jun., Covell, J. W., Kaiser, G. A., and Braunwald, E. (1965b). American fournal of Physiology, 209, 919.

Stern, S., and Eisenberg, S. (1969). American Heart fournal, 77, 192

Taylor, S. H., MacDonald, H. R., Robinson, M. C., and Sapru, R. P. (1967). British Heart fournal, 29, 352 .

Taylor, S. H., Majid, P. A., and Sharma, B. (1970). Postgraduate Medical fournal, November Supplement, p. 57.

Taylor, S. H., and Sharma, B. (1971). British Heart Fournal. In press.

Whitsitt, L. S., and Lucchesi, B. R. (1967). Circulation Research, 31, 305.

\title{
In-vitro Inhibition of Leucocyte Migration in Crohn's Disease by a Sarcoid Spleen Suspension
}

\author{
J. M. T. WILLOUGHBY, D. N. MITCHELL
}

\section{British Medical fournal, 1971, 3, 155-157}

\section{Summary}

A Kveim suspension has been shown to inhibit the migration of leucocytes in vitro from 12 out of 18 patients with Crohn's disease but to have no comparable effect on leucocytes from patients with ulcerative colitis or from a group of patients with other diseases. These findings provide further evidence of cross-reactivity or of a possible aetiological link between Crohn's disease and sarcoidosis and suggest a further immunological distinction between Crohn's disease and ulcerative colitis.

\footnotetext{
Departments of Gastroenterology and Experimental Pathology, St. Bartholomew's Hospital, London E.C.1

J. M. T. WILLOUGHBY, B.M., M.R.C.P., Research Associate and Honorary Lecturer in Medicine

M.R.C. Tuberculosis and Chest Diseases Unit, Brompton Hospital, London S.W.3

D. N. MITCHELL, M.D., Member of Scientific Staff
}

\begin{abstract}
Introduction
A positive Kveim reaction has in the past been regarded as highly specific for sarcoidosis (Siltzbach, 1967). However, in a recent study Kveim tests were made with a carefully validated test suspension prepared from a sarcoid spleen (K12) in a series of 74 patients with definite or probable Crohn's disease (Mitchell, Cannon, Dyer, Hinson, and Willoughby, 1970). Microscopical readings of the biopsy specimens showed that $38(51 \%)$ had a positive Kveim test. Moreover, 12 out of 19 patients with clinically definite or histologically confirmed Crohn's disease had a positive reaction both to $\mathrm{K} 12$ and to another extensively validated test suspension (Hurley) prepared from a different sarcoid spleen.

The nature of the Kveim reaction is not understood, but it seems probable that it may represent a special class of reaction, possibly a "delayed, delayed-type" of cell-mediated cutaneous hypersensitivity response (Hart and Rees, 1967). Since the leucocyte migration test is of proved value as an in-vitro correlate of cell-mediated hypersensitivity (Søborg and Bendixen, 1967; Bendixen and Søborg, 1969) and had already been found to mediate a specific response to sarcoid spleen suspensions in sarcoidosis (Hardt and Wanstrup, 1969), it was decided to investigate the potential role of sarcoid and of normal spleen suspensions in the in-vitro inhibition of leucocytes in Crohn's disease, and to include for comparison similar tests in patients with ulcerative colitis and other conditions.
\end{abstract}

